\title{
Year Zero for the Archaeology of Iraq: Some Additional Comments
}

\author{
Harriet Crawford \\ Chairman \\ British School of Archaeology in Iraq
}

Roger Matthews has raised a number of fundamental issues, and I would like to augment one or two of the points he has made before going on to look in more detail at the future of the British School of Archaeology in Iraq (BSAI). A new start is desperately needed in Iraq: such a start needs, among many other things, to include a massive training programme for existing staff in the State Board for Antiquities and Heritage. International sanctions have prevented Iraqis from attending any form of training or education outside their own country. Their access to new technology, especially computer-based technology has been virtually nil. When the State Board for Antiquities and Heritage is up and running again and has had the time to decide on its priorities, it is very much to be hoped that the international community will facilitate further training in a wide variety of areas. These will probably include conservation, computer studies, new surveying and GIS techniques, and a raft of museum and heritage studies. Some plans are already in place, but practical difficulties - in getting travel documents for example - and in acquiring basic foreign languages, mean that no training has yet taken place. When the security situation improves it may prove more cost-effective for people to travel to Baghdad to provide introductory courses there, and the BSAI would hope to be involved in any such programme.

I am sure that Matthews is correct in saying that the old imperialist attitudes are now totally inappropriate. In the future we must work towards genuine cooperation on an equal footing between foreign and local scholars. This cooperation should ideally include the development of joint research programmes which pay more than lip service to the needs and concerns of Iraq itself, as well as actual excavations. As Matthews suggests, it should also include bilingual publications and assistance with improving the printing facilities in Iraq so that their publications, such as the vital journal Sumer, can be produced to international standards. New methods of publication, such as CDROMs and web publication, also need to be explored. This may be especially the case for minority interest topics which are never going to cover the costs of traditional printon-paper publication in small print runs. More attention to local people is also vital. Some expeditions already make considerable efforts to interest, educate and involve them in the projects under way in their neighbourhoods. The London Bahrain Archaeological Expedition, of which I was a part, had an active education programme involving local schools and other local bodies. Television and newspaper articles were also useful for reaching the local people, and we all had to learn how to put across our enthusiasm and the importance of what we were doing. Local involvement with a project is a far better guarantee of safety for the site and its artefacts than armed guards.

Papers from the Institute of Archaeology 14 (2003): 7-8 
So where does the BSAI stand in all this? What follows is my own personal view and not that of the Council of the School, which will be debating this vital question later this year. We all start from the premise that the School is desperate to return to Iraq in one way or another. I think everyone is agreed that the proto-imperial model of the past is impossible on both moral and financial grounds, but there are still a number of possibilities to consider. The minimalist position is that no permanent base is necessary. It has, for example, proved possible to carry out work in both Bahrain and Kuwait without the support offered by a British School. However, the situation in Iraq may well be different, and we shall not know the final nature of the administration for some time yet. Then there is the possibility of a joint Iraqi/British institute of some kind. The Italians have such a joint venture, but given our precarious financial situation it may not possible to make a long-term financial commitment even if it is judged politically desirable to do so. Cooperation with one or more foreign groups also needs to be explored. The Americans are hoping to set up a big new humanities institute in Baghdad, but we might risk being a very small fish in their pool, and it is far from clear how the Americans will be regarded in the 'new' Iraq. Perhaps the most interesting possibility is to explore the potential of a European venture involving three or more members of the EU. The French and Germans have their own arrangements, but countries such as Finland, Holland, Poland and Denmark all have scholars who have been very active in the region. In principle this sort of group might unlock EU funding which would be invaluable, though no-one underestimates the problems of working the EU system!

There are many other problems to be solved. There is a real lack of younger archaeologists in the field of Mesopotamian studies in this country partly because it has been impossible to carry out research in Mesopotamia for the last 13 years, partly because of the declining number of specialist staff and courses in universities across Europe and partly, perhaps, because we the specialists have not been very good at 'selling' the subject. There has also been a sharp decline, in Britain at least, in the level of public funding available for research in this sort of field. All these factors feed on each other and compound the problem. In summary, bodies such as the BSAI face a tough time ahead, but in spite of everything, are determined to return to Baghdad. The archaeology of Iraq has so much still to offer the world, and I hope and believe that we in Britain still have something important to offer Iraq. 